Recorrendo à diferença entre os estatutos de infância em Descartes e Rousseau, procura-se problematizar a tese apresentada em Infância e ilusão (psico)pedagógica em torno das condições de possibilidade da infância nos tempos contemporâneos.

Infância moderna; filosofia da educação; fundamentos da educação

\section{IS THERE THE}

CHILDHOOD LEANDRO DE LAJONQUIERE SPEAKS ABOUT?

Revisiting the difference between the statutes of childhood in Descartes and Rousseau, an attempt is made to question and turn controversial the thesis presented in Childhood and (psycho)pedagogic illusion about the possibility of there being the proper conditions for childhood in contemporary times. Modern childhood; the philosophy of education; the fundamentals of education

\section{EXISTE A \\ INFÂNCIA DE QUE FALA LEANDRO DE LAJONQUIERE?}

D or mais que um autor tenha escrito livros e por mais que tenha sido citado, duvido que, quando citado por um outro que ele admira, ele não vá procurar avidamente, na leitura da obra em questão, o que é que este segundo aproveitou de seus escritos. Às vezes, muito raramente, com esse comportamento, temos alegrias - e este foi o meu caso quando cheguei a uma página do novo livro de Leandro de Lajonquière, Infância e ilusão (psico)pedagógica (São Paulo, SP: Vozes, 1999), em que ele remete o leitor a um livrinho meu, o Infância, educação e neoliberalismo (São Paulo, SP: Cortez, 1996). É que, no meu livrinho, eu dizia que a escola, hoje, vai ganhando aspectos que lembram o ambiente reificado das atuais academias de ginástica. Leandro aproveita o mote para ligar o culto ao corpo - próprio das academias - ao culto ao físico posto à prova - próprio dos campos de batalha -, e com isso segue seu percurso de imaginar a escola atual como, na linha de Foucault, algo que se parece mais com a vida nos hospitais e nas

- Professor de Filosofia da Universidade Estadual Paulista, campus de Marilia, e da Universidade Auckland, na Nova Zelândia. 
prisões do que propriamente com o que deveria ser a escola, talvez um lugar de superação da infância.

A vida nos hospitais e nas prisões, e também nos campos de batalha, se levássemos ao limite o pensamento de Kant no célebre ensaio "Resposta à pergunta 'O que é o Iluminismo?", seria o lugar de máxima menoridade, dado que aí o homem perde totalmente a capacidade de julgar qualquer coisa pelo seu próprio entendimento e decidir pela própria razão, e, como se sabe, Kant fez destas capacidades a definição daquele que saiu da condição de menoridade. $O$ argumento inteiro do livro de Leandro, posto nos meus termos, seria este: a escola, local privilegiado da infância, em vez de cuidar $\mathrm{da}$ infância para que ela se realize, infantiliza e, portanto, não permite a realização da infância, que é o seu acabamento. Ao final de um percurso, deveríamos ter o término da infância e a opção pela vida adulta, isto é, o adulto da modernidade, ou seja, o indivíduo, aquele que é sujeito: o homem "consciente de seus pensamentos e responsável pelos seus atos”. Leandro de Lajonquière, como eu o leio, bate nesta tecla, construindo então um belo livro, mas, ao mesmo tempo, um livro que, a meu ver, fala mais do passado que do presente (tomo esses termos muito mais lógica e tematicamente do que temporalmente). Eu explico.

$\mathrm{O}$ argumento de Leandro me parece ser o seguinte: todo o processo escolar atual tem algo de culto à infância, mas não em um sentido correto, e sim no sentido perverso de tornar infantilóides aqueles que, em princípio, deveriam gozar a infância e, enfim, sair dela. Haveria então o império do infantil, ou melhor, do infantilismo, sobre a vida adulta (pelo menos dentro da escola). Haveria então o império da lei dos pequenos contra a legalidade da polis adulta. Pois bem, eu gosto do livro do Leandro porque ele é bem escrito e instigante, mas não concordo com seu argumento mais geral e, pelo que entendi, central.

Eu ainda continuo filósofo e, por vício de formação e de profissão, tendo a citar menos cientistas e psicólogos e mais, obviamente, filósofos. E eu creio que a infância, como ela aparece na escola e como ela circula na mentalidade dos professores e pais, seria mais bem retratada se Leandro abrisse mão de vê-la pelos óculos de suas leituras de psicólogos e psicanalistas (ainda que ele faça leituras críticas e rigorosas, como faz mesmo), e pudesse adentrar no campo filosófico e pedagógico. Se ele fizesse isto, viria aos seus olhos não a idéia de que a escola hoje é o reino da infância e do infantilismo contra o reino dos adultos iluministas. Viria aos seus olhos, sim, a idéia de que a escola hoje e seus professores trabalham com uma idéia de infância que é um misto das duas grandes concepções de infância do Ocidente moderno, exata- 
mente no limite de esse Ocidente moderno desaparecer. A que mistura me refiro? À mistura entre a noção cartesiana de infância e a noção rousseauniana de infância, exatamente quando ambas essas noções já não dão conta da infância que sobrou. Vou brevemente recordar o leitor sobre essas duas noções de infância.

Em termos completamente simplificados (caso o leitor queira algo mais sofisticado, ele deve ir ao meu livro $O$ que é filosofia da educação, Rio de Janeiro, RJ: DP\&A, 2000), a infância para Santo Agostinho e para Descartes era um momento que deveria ser superado para o bem da verdade e, portanto, para o bem da filosofia, que, afinal, é a busca da verdade. Como se sabe, Descartes via na menoridade uma situação na qual o entendimento ficava nublado pela imaginação e a vontade racional ficava subalternizada pelos desejos e paixões, estas, por sua vez, vindas mais do corpo do que do interior cuja passagem seria a glândula pineal, o local de contato entre o sensível e o supra-sensível. Sendo assim, toda educação cartesiana seria um trabalho de abafamento da história, da memória, da imaginação e do corpo, em favor do entendimento inteligente e da vontade livre e racional, para que o homem possa então tornar-se indivíduo pleno - alguém consciente de seus pensamentos e responsável pelos seus atos.

Essa concepção de infância sobrevive até hoje (talvez, até mesmo, na própria formação intelectual de Leandro, dado seu iluminismo freudiano). Mas ela é típica, em termos filosóficos (e não históricos), do século XVII. Já no século XVIII ela é completamente abalada pelos protagonizadores do que no século XIX e XX veio a ser conhecido mais institucionalmente como Movimento da Escola Nova (talvez o inimigo interno de Leandro). Trata-se da concepção de infância inaugurada, principalmente, por Rousseau. Neste caso, também muito simplificadamente, o que temos é que a infância, em vez de ser vista como uma época que deve passar e acabar, é uma época que deve passar, mas não acabar de vez. Ou seja, o homem só encontra a verdade - aquilo que o filósofo por dever de profissão deve procurar - quando ele, a quatro paredes, na sinceridade do coração, tem a certeza. Ou seja, quando o seu íntimo ainda não foi maculado pela máscara social e corrompido pela reificacão, digamos, necessária do mundo adulto. Assim, para Rousseau, toda boa educação é negativa, deve funcionar para preservar o "bom selvagem" que há na criança, que é metaforicamente posto como o ser de coração sincero e, portanto, o único que ainda pode julgar o certo e o errado, e não só o verdadeiro e o falso, como seria o sujeito cartesiano. Contra um indivíduo que deve apagar os vestígios da infância, Rousseau modela seu indivíduo moderno como aquele que deve superar a infância, mas guardar dela o coração sincero, afinal, sua única oportunidade 
de ser alguém que cultua a verdade $\mathrm{e}$ a justiça uma vez adulto.

Ora, a meu ver, temos aí a dupla concepção de infância da modernidade, que está na cabeça de pais e mestres, de maneira confusa e cruzada. Em certos momentos pais e mestres elogiam a inocência de seus filhos e alunos, apontando-os como modelo contra o adulto reificado, em outros momentos eles punem qualquer sinal de infantilidade, em nome do ideal cartesiano de vida adulta. Essa confusão funcionou. A Escola Tradicional e a Escola Nova viveram e vivem com professores cuja cabeça é exatamente montada por essas duas concepções de infância - atormentando aquele professor que desconfia que não está sendo coerente, mas não afligindo os pais, que acham que criança "é assim mesmo", ou seja, são anjos e demônios ao mesmo tempo.

Tudo isso continuaria funcionando se vivêssemos na modernidade. Mas o problema é que, pelo menos desde 1979, com a publicação de $A$ condição pós-moderna, de Lyotard, e com o a publicação de $A$ filosofia e o espelho da natureza, de Rorty, começamos a desconfiar que talvez a modernidade, em vários aspectos, tenha se exaurido, e que estejamos vivendo numa época mais de busca de dissenso (Lyotard) do que de busca de consenso (Habermas), e de busca de edificação em prol de conseguirmos viver o mundo plural que se abre (Rorty) do que a inevitabilidade de busca de unidade moderna de controles individuais e coletivos (Foucault). No meio disso, dois extremos. Primeiro extremo. 
Nos países ricos, desde o início da década de 80 do século XX, paira no ar a idéia de que o indivíduo moderno é uma meta irrealizável, e que então temos de criar novas metas. E, portanto, a educação não tem mais por que querer tirar da criança, puxando pelos cabelos (uma das etimologias da palavra educação indica este ato), o adulto enquanto indivíduo moderno. Segundo extremo. Nos países pobres, o aparecimento de intelectuais que sabem exatamente que este sentimento de fim do sujeito e de fim da infância permeia a população, mas que, no caso, isso acontece sem que tenhamos o que destruir para poder pôr outra coisa no lugar (como nos países ricos), pois nossas crianças, na maioria, nunca usufruíram da condição infantil enquanto ganho de direitos sociais como nos países ricos.

Assim, o drama de pais e professores nos países pobres não seria aquele apontado por Leandro. Seria em parte, mas não totalmente. Leandro acerta quando capta a idéia de que a escola infantiliza, mas discordo dele quando ele revira isto no seu livro não abrindo mais páginas para a situação que me parece dar melhor conta do drama escolar hoje: queremos que a infância ocorra, seja ela pela via cartesiana ou rousseauniana, mas já não podemos mais reivindicar isso quando, naqueles países que "puxam a história", há toda uma argumentação teórica que nos mostra que, sabe-se lá por quê, pais e professores não acreditam mais na infância.

Recebido em 04/2000. 